\title{
Uriel Quesada, \\ Mar Caníbal
}

\section{José Pablo Rojas González}

Recepción: 13 de agosto de 2016 / Aprobación: 28 de setiembre de 2016

a nueva novela de Uriel Quesada (San José, Costa Rica), Mar Caníbal, está dividida en 11 capítulos y un epílogo. A lo largo de estos apartados, la narración trata de rescatar la memoria de Chalito/Gonzalo (un gay) y la de los personajes vinculados con él durante la mayor parte de su vida. No extraña, entonces, que el texto guíe al lector por diferentes espacios y diferentes tiempos, que nos lleve por los espacios del recuerdo... Los lectores, por lo anterior, debemos construir la historia de Gonzalo y la de su familia y amigos, debemos participar de un juego literario que, además, es - desde mi perspectiva- un importante foco de inspiración política. Esta nueva novela costarricense, en efecto, reflexiona a lo largo de sus páginas sobre diferentes formas de marginación, como también sobre las estrategias de resistencia que existen para afrontar el sojuzgamiento. Una de esas estrategias para rechazar el aprisionamiento subjetivo es la ficción. Se insiste, por ello, en la importancia de hacer ficción de la vida, lo cual, finalmente, no es sino una forma de hacerla nuestra. Chalito así lo entiende en la historia planteada en este nuevo texto literario. Uno de los narradores de Mar Caníbal nos lo hace saber en los siguientes términos: "quizás ya desde ese entonces sabía que solamente bajo la piel de los personajes de ficción, Chalito podía ser quien era, o ver a los demás desde otros ángulos" (Quesada, 2016, p. 63).

La noción de ficción se debe comprender de acuerdo con lo que plantea Roland Barthes en su Lección Inaugural (2003): hacer ficción es hacer literatura. La literatura es, entonces, un juego ficcional. Es un juego en la medida en que altera el lenguaje y travesea los poderes que lo habitan. Por eso, también, es posible decir que la literatura es revolucionaria: la literatura revoluciona el lenguaje y las representaciones que en él encontramos. No extraña que la ficción sostenga a Chalito, como lo hace con Natalio Rojas, otro de los protagonistas de esta historia de vida que se mueve entre el Caribe y Cartago. Como sucede en El gato de sí mismo (2005), Mar Caníbal es narrada principalmente por sujetos excluidos, quienes además hacen de la memoria la herramienta fundamental para referirnos su historia y la de los otros vinculados con ellos.

1 Costarricense. Máster Académico en Literatura Latinoamericana por la Universidad de Costa Rica (UCR). Profesor Instructor de la Escuela de Estudios Generales de la UCR. Correo electrónico: jprojasg@gmail.com 
La memoria, por supuesto, es una construcción ficcional y de ello se deduce la importancia que Chalito y Natalio Rojas -su "Víctor Hughes"- le dan a este recurso. Véase lo que le dice Natalio a Chalito sobre un cuadro que tenía en su casa: "-Ese lugar no existe -se apuró a aclarar el viejo como si ya supiera la pregunta que Chalito tenía en la cabeza-. Es una fantasía, pero me gusta. Uno no puede vivir solo de la realidad, ¿no te parece?” (Quesada, 2015, p. 80). Hablo de Natalio Rojas como de un Victor Hughes, ya que, como sucede en El siglo de la luces (1989), de Alejo Carpentier, este personaje es un gran contador de historias y una especie de guía para Chalito, un "padrino gay" que le ofrece su experiencia de vida como una herramienta de resistencia y de lucha por la libertad. Afirma Natalio: "Nada de lo que voy a contarte es mentira, Gonzalo. Tampoco es totalmente verdad ... Nosotros los viejos, buenos recordadores, solamente podemos dar lo que el corazón nos permite. En el mío hay mucha memoria" (Quesada, 2016, p. 101).

La activación de la memoria, desde mi punto de vista, permite una relectura/ reescritura de la vida y es esto, precisamente, lo que nos ofrece Mar Canibal: una reelaboración literaria de la existencia que es, al mismo tiempo, personal y colectiva. Estamos ante una relectura de la historia, la cual es recontada -en la novela de Uriel- desde la perspectiva de unos sujetos a los que no se les ha permitido hablar: me refiero, en este caso, a los "homosexuales". A partir de lo anterior, es posible afirmar que la novela Mar Caníbal es literatura gay; es decir, estamos hablando de una literatura que se sale del clóset y confronta los discursos oficiales. Es una literatura que pone en crisis las formas de dominación que se establecen a partir de la sexualidad, pero también a partir de otras variables sociales como la clase, el género, la etnia, etcétera. La literatura gay es, por tanto, contestataria. Podemos vincular lo anterior con lo que afirma Chalito/Gonzalo (ya como adulto) sobre sí mismo. Afirma Gonzalo: "a mediados de los setenta yo era apenas un mocoso desesperado por saber. Si ahí residiera mi maldad, habría que decir que la maldad reside en la búsqueda de conocimiento. Pero para el viejo, ser malo simplemente podía indicar no seguir las reglas, y en eso me declaro perverso" (Quesada, 2016, p. 151).

Por supuesto, lo que ahora sostengo hay que vincularlo con el contexto que nos plantea la nueva novela de Quesada. Ya señalé que es una novela que se mueve entre el Caribe y Cartago, tengo ahora que agregar que se ubica en la década de 1970 y que retrata una sociedad conservadora/patriarcal. Este espacio/tiempo/organización social es necesario referirlo, ya que la novela cuestiona la identidad nacional costarricense haciéndonos ver lo que no queremos ver de nosotros mismos, es decir, que somos una sociedad sexista, racista y discriminatoria. Mar Caníbal revela las estructuras sociales que, hasta nuestros días, han mantenido los imaginarios nacionales costarricenses y lo hace desde el núcleo duro: desde "la familia". La nueva novela de Uriel Quesada nos muestra las contradicciones que conforman esta institución social, una institución que se funda y reproduce en sus miembros. La familia, en el texto 
literario, se apellida Malverde, y desde el padre y por él, parece ser una familia condenada. La familia, en los términos expuestos en la novela, es un espacio del cual hay que huir y esto es sobre todo cierto para los sujetos que menos calcen dentro del paradigma patriarcal que sustenta dicha institución.

Cuando, en general, se habla del sujeto nacional costarricense no se hace referencia a un "homosexual" o a una negra, solo por dar dos casos específicos que toma en cuenta la novela de Uriel. Estos "sujetos-otros" han sido silenciados desde el núcleo familiar. Este silencio se ha extendido hasta la historia oficial y, por ello, no forman parte de la realidad nacional. O, si son tomados en cuenta, son asumidos como los "sujetos inferiores" de dicha realidad. Son "subhumanos" y, por lo tanto, deben estar subordinados. Como es claro, es la supuesta inferioridad la que justifica, desde una postura hegemónica, el aprisionamiento de personajes como el viejo y homosexual Natalio Rojas o como el de la negra Ventura (una hija comprada por Gregorio Malverde, el pater familias). Estos personajes son acusados por el hecho de existir, son personajes que, además, aprehenden -en diverso grado- su culpabilidad por "ser quienes no deben ser". El texto literario lo expone en los siguientes términos en relación con Natalio Rojas y su "sobrino":

Si Natalio Rojas y su sobrino habían sido tolerados por la gente bien, ahora se le daba la espalda al perverso, se le quitaba el saludo, se le impedía entrar a los clubes. De esta forma, en la historia no oficial de la ciudad quedó registrada otra prueba de la furia incontenible de Dios ante los desvíos innombrables de los hombres. Que tomaran nota quienes frecuentaban la casa de Natalio, que entendieran las consecuencias quienes siquiera se atrevieran a abrigar en el pensamiento un pecado nefando (Quesada, 2016, p. 73).

Así, según la lectura que propongo de la novela, la sociedad costarricense -aunque es claro que lo que estoy apuntando va más allá de los límites de lo costarricense- se mantiene a partir del canibalismo simbólico (pero con consecuencias materiales) que sustenta la valía de unos sujetos en menosprecio de otros, que pueden y deben ser devorados. El nacionalismo que vivimos es, entonces, caníbal. Los nacionalismos que no reconocen la pluralidad, la diversidad y, sobre todo, el valor humano de los otros, terminan alimentándose con su propia especie. El nacionalismo caníbal es una reducción de la humanidad, un atentado contra la humanidad, porque, siguiendo a Caparrós (2015), quien excluye a los de otro país puede, por el mismo procedimiento, excluir sin mucha dificultad a los de otra provincia, a los de otra religión, a los de otro género, a los de otra sexualidad, a los de otra etnia, etcétera. Esto es lo que, precisamente, sufre la hija negra de la blanca familia Malverde a la que siempre ven como una extraña, de la cual hay que desconfiar, a la cual hay que controlar y sobre la cual recaen todas las acusaciones.

Mar caníbal, desde su título, hace referencia a un espacio (para mí, el título es una metáfora del espacio social mismo), pero -a partir de lo explicado-hace sobre todo referencia a una práctica: a la práctica de servirse del otro hasta 
agotarlo. La dominación implica una anulación del otro, una anulación del deseo del otro en todos los niveles. No extraña que la novela de Quesada nos lleve, con sus personajes principales, a buscar la libertad; la novela nos muestra la importancia de tener la voluntad por acabar con las ataduras, a través de diversos medios: la huida, la resistencia amorosa, la sobrevivencia misma frente a la insistencia de la muerte social y física. Mar Caníbal, finalmente, no es una novela que nos entregue a la desesperación; hay formas de escape, hay espacio (y aquí retomo el nombre de la negra Ventura), para la (a)ventura, es decir, para la felicidad: para la felicidad de "no dejarse domesticar" (como sucede con esta mujer que termina de "cimarrona"); para la felicidad de poder contar "mi historia de vida" (como sucede con el viejo Natalio Rojas y con Gonzalo, el adulto que narra), para la felicidad de poder vivir una "nueva gramática de los cuerpos" (como lo experimenta el adolescente Chalito, al descubrirse pleno en su sexualidad). La (a)ventura, sin embargo, no está ausente de sufrimiento o de peligros. Aventurarse tiene su precio, como podrán colegir luego de su lectura de Mar Caníbal. La aventura está ahí donde los caminos se bifurcan e inicia con la escogencia de nuestro propio recorrido vital.

\section{Referencias}

Barthes, Roland. (2003). Placer del texto y Lección inaugural. Buenos Aires: Siglo XXI. Caparrós, Martín. (2015). El hambre. Barcelona: Anagrama.

Carpentier, Alejo. (1989). El siglo de las luces. Madrid: Cátedra.

Quesada, Uriel. (2005). El gato de sí mismo. San José: Editorial Costa Rica.

Quesada, Uriel. (2016). Mar Caníbal. San José: Uruk Editores. 